\title{
Bronchopulmonary Dysplasia Is Not Associated with Ultrasound-Defined Cerebral White Matter Damage in Preterm Newborns
}

\author{
OLAF DAMMANN, ELIZABETH N. ALLRED, LINDA J. VAN MARTER, \\ CHRISTIANE E.L. DAMMANN, AND ALAN LEVITON FOR THE DEVELOPMENTAL \\ EPIDEMIOLOGY NETWORK INVESTIGATORS
}

Department of Obstetrics, Prenatal Medicine and Gynecology, Hannover Medical School, 30623 Hannover, Germany; Department of Pediatric Pulmonology and Neonatology [O.D., C.E.L.D.], Hannover Medical School, 30623 Hannover, Germany; Neuroepidemiology Unit [O.D., E.N.A, A.L.], Department of Neurology, Children's Hospital and Harvard Medical School, Boston, Massachusetts 02115, U.S.A.;

Department of Biostatistics [E.N.A.], Harvard School of Public Health, Boston, Massachusetts 02115, U.S.A.; Department of Pediatrics [L.J.V.M.], Children's Hospital and Harvard Medical School, Boston, Massachusetts 02115, U.S.A.; Division of Newborn Medicine [L.J.V.M.], Brigham and Women's Hospital,

Boston, Massachusetts 02115, U.S.A.; and Division of Newborn Medicine [C.E.L.D.], Department of

Pediatrics, New England Medical Center, Tufts University Medical School, Boston, Massachusetts 02111, U.S.A.

\section{ABSTRACT}

Bronchopulmonary dysplasia (BPD) and cerebral white matter damage (WMD) are neonatal disorders that occur most commonly in those who are born much before term. In a large multicenter database, we sought to determine whether the two disorders occur together more frequently than expected and whether BPD and other neonatal respiratory characteristics are more common among infants who develop ultrasound-defined WMD than among those who do not. In a sample of 904 infants who were born before the 30th week of gestation and survived until 36 wk postmenstrual age, we did not find a co-occurrence of BPD and WMD above what would be expected by chance. Confounding does not seem to account for this lack of associa- tion between WMD and BPD. In conclusion, our findings do not support the hypothesis that BPD contributes to the occurrence of sonographically defined WMD. (Pediatr Res 55: 319-325, 2004)
Abbreviations
BPD, bronchopulmonary dysplasia
CI, confidence interval
CP, cerebral palsy
MRI, magnetic resonance imaging
OR, odds ratio
WMD, white matter damage

Preterm infants are exposed to a number of antenatal and postnatal challenges that, in concert with their immaturity, render them susceptible to a wide range of neonatal disorders. Among these, bronchopulmonary dysplasia (BPD) and cerebral white matter damage (WMD) are prominent entities.

BPD was initially identified as a chronic neonatal lung disease that occurred in preterm infants who were exposed to prolonged ventilation with high airway pressure and high inspired oxygen concentrations (1). More recently, a "new"

Received February 18, 2003; Accepted July 13, 2003.

Correspondence: Olaf Dammann, M.D., Perinatal Infectious Disease Epidemiology Unit, OE 6415, Hannover Medical School, 30623 Hannover, Germany; e-mail dammann.olaf@mh-hannover.de

Supported by National Institutes of Health (NS027306, NS040069, HL004436), United Cerebral Palsy Research and Educational Foundation (EH-003-98), the Charles H. Hood Foundation (Boston, MA, U.S.A.), and the Wilhelm-Hirte Stiftung (Hannover, Germany).
BPD was defined as a form of neonatal chronic lung disease, characterized by aberrational lung alveolarization and vascular development (2). Changes in neonatal practice, including the introduction of exogenous surfactant, increased use of antenatal glucocorticoids, and sophisticated ventilatory support strategies, might play a role in this changing clinical phenomenology of BPD. Antenatal effects apparently gain pathogenetic importance (3), and major research emphasis is being placed on inflammatory pathomechanisms (4). The current terminology has now returned from "chronic lung disease" to BPD (5). The new definition of BPD_- "receiving $\mathrm{O}_{2}$ at 36 wk postconceptional age" - has been shown to be a better predictor of abnormal pulmonary signs and symptoms at age 2 (83\%) (6) than the $38 \%$ achieved by previously suggested definition of BPD_- "receiving $\mathrm{O}_{2}$ at $28 \mathrm{~d}$ of life" (7). 
Neonatal WMD is a term applied to any abnormality identified in the neonatal cerebral white matter. The term avoids two errors: attributing a single cause (8) and attributing histologic diagnoses to abnormalities identified by ultrasound (9). Over the past decades, discussions of WMD pathogenesis have revolved around two main concepts: hypoxia-ischemia and infection/inflammation $(10,11)$.

There are several ways in which BPD and WMD might be related. First, both occur predominantly in preterm infants. Thus, prematurity might be a predisposing factor for both. Second, what contributes to prematurity might contribute to both BPD and WMD. One candidate risk factor is antenatal infection/inflammation (12). Third, postnatal lung disease might contribute to brain structural abnormalities and functional deficits via the hypoxia-ischemia pathway (13-16). However, caution has been advised when discussing a possible link between BPD and WMD (17). In this article, we explore the relationship between BPD and WMD identified on neonatal cranial ultrasound images.

\section{METHODS}

Sample. The multicenter cohort of the Developmental Epidemiology Network Study comprised 1607 VLBW infants (500-1500 g) who were born between January 1, 1991 and December 31, 1993, at five hospitals in Boston, New York City, and New Brunswick, NJ, U.S.A. The study was designed to identify antecedents of WMD, and each infant had at least one of three cranial ultrasound scans at times established by the study design.

Birth weight-defined samples contain a disproportionate number of growth-restricted infants at higher gestational ages (18). To maximize statistical power while at the same time minimizing the risk of including too many gestationally older growth-restricted infants, we limited our study sample to infants who were born before the 30th wk of gestation. Moreover, an infant had to survive long enough to have BPD and WMD ascertained. Thus, to be in the present sample, an infant also had to survive to at least $36 \mathrm{wk}$ postmenstrual age (see definition of BPD below). Among these 904 infants, 46 (5\%) had an echolucency identified on neonatal cranial ultrasound and 169 (19\%) had BPD.

Ultrasound data. Manuals were created to standardize the ultrasound scanning procedure and the interpretation of scans. The six standard coronal views were those recommended by Teele and Share (19). The five sagittal views include the midline, each lateral ventricle, and lateral to each lateral ventricle. Protocol scans were obtained once during the first 4 postnatal days (median, day 1), once between postnatal days 5 and 15 (median, day 7), and once between days 15 and 60 (median, day 21). Scans were brought to a consensus committee when either of two independent readers identified an echolucency anywhere in the cerebral white matter. The final diagnosis of echolucency required consensus among a minimum of three sonologists reading together about the presence, size, and location of all hypoechoic white matter abnormalities.

Definitions. The major outcome is the presence of an echolucent image anywhere in the white matter on neonatal cranial ultrasound. We have previously described our protocolbased diagnostic process by committee $(20-23)$. As in previous papers (24-26), we defined BPD as oxygen dependence at 36 postmenstrual weeks (6). Although this definition might be considered suboptimal because of its association with physicians' treatment decisions, this is currently the most widely used operational definition. Using this definition allows us to compare our findings with those of others.

Placenta data were collected using forms designed for this study (27-30), as were maternal and neonatal clinical data. In addition, we interviewed mothers of study infants. The reader is referred to the above publications for definitions of variables displayed in the tables. The study was approved by Institutional Review Boards at all participating hospitals, and written informed consent was obtained.

Analytical approach. The underlying hypothesis of our analysis is that WMD and BPD are associated. To evaluate the association between WMD and BPD, we compared their observed co-occurrence to that expected if they were independent of one another in the entire sample and in strata defined by gestational age (Table 1). If two phenomena occur independent of one another, then their joint observed prevalence should not be different from the product of their individual observed prevalences (multiplicative rule of probability). This product is equal to the expected joint prevalence. The relationship between joint observed and expected frequencies is the basis for the calculation of $\chi^{2}$ statistics (31).

We then sought common antecedents by tabulating the prevalence of potential correlates among cases of echolucency and BPD and their respective controls (Tables 2-4). Next, we selected variables that were associated with both BPD and WMD at $p<0.25$ (32) for multivariable modeling. We created logistic regression models predicting white matter echolucency that included BPD and all potential confounders. Finally, we sequentially removed variables that seemed not to add infor-

Table 1. The co-occurrence in the entire sample $(N=904)$ of $W M D$ and BPD does not appreciably exceed what would be expected if the occurrence of each were independent of the other

\begin{tabular}{|c|c|c|c|c|}
\hline Sample & WMD & BPD & Observed* & Expected $\dagger$ \\
\hline \multirow[t]{4}{*}{ Full } & Yes & Yes & 10 & 9 \\
\hline & & No & 36 & 37 \\
\hline & No & Yes & 159 & 160 \\
\hline & & No & 699 & 698 \\
\hline \multirow[t]{4}{*}{$<26$ wk } & Yes & Yes & 5 & 5 \\
\hline & & No & 12 & 12 \\
\hline & No & Yes & 51 & 51 \\
\hline & & No & 131 & 131 \\
\hline \multirow[t]{4}{*}{$26-28 \mathrm{wk}$} & Yes & Yes & 4 & 4 \\
\hline & & No & 17 & 17 \\
\hline & No & Yes & 95 & 95 \\
\hline & & No & 390 & 390 \\
\hline \multirow[t]{4}{*}{$>28 \mathrm{wk}$} & Yes & Yes & 1 & 1 \\
\hline & & No & 7 & 7 \\
\hline & No & Yes & 13 & 13 \\
\hline & & No & 178 & 178 \\
\hline
\end{tabular}

* The observed occurrence is the number of children observed in each category defined by the characteristics listed on the left.

$\dagger$ The expected frequency is the product of the individual observed probabilities of WMD and BPD occurrence: $\mathrm{P}(\mathrm{WMD} \cap \mathrm{BPD})=\mathrm{P}(\mathrm{WMD}) \mathrm{P}(\mathrm{BPD})$. 
Table 2. Column percentages of infants with/without WMD and with/without BPD whose mother had the characteristic listed on the left

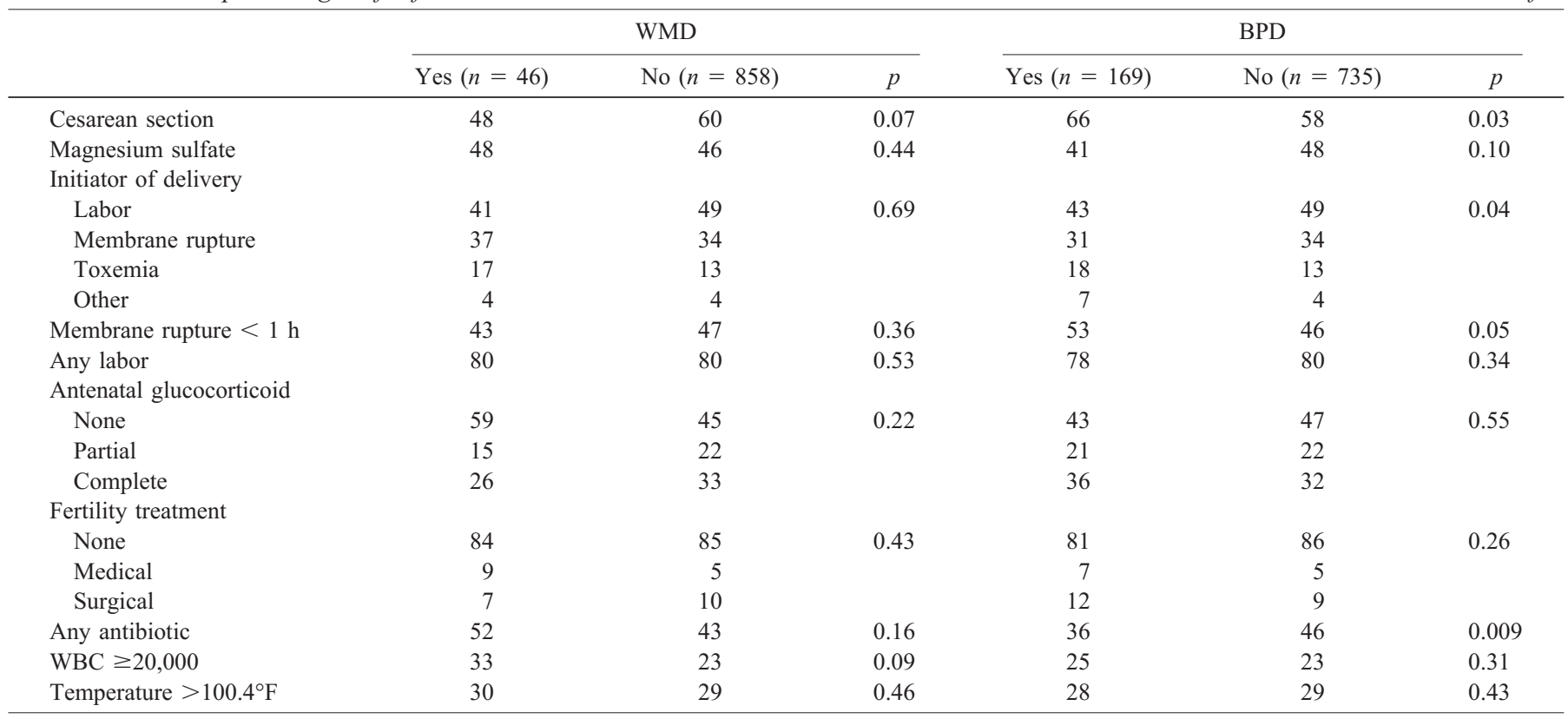

Table 3. Column percentages of infants with/without WMD and with/without BPD who had the characteristic listed on the left

\begin{tabular}{|c|c|c|c|c|c|c|}
\hline & \multicolumn{3}{|c|}{ WMD } & \multicolumn{3}{|c|}{ BPD } \\
\hline & Yes $(n=46)$ & No $(n=858)$ & $p$ & Yes $(n=169)$ & No $(n=735)$ & $p$ \\
\hline \multicolumn{7}{|l|}{ Gestational age } \\
\hline$<26$ wk & 37 & 21 & 0.06 & 33 & 19 & $<0.001$ \\
\hline $26-28 w k$ & 46 & 57 & & 59 & 55 & \\
\hline$>28 \mathrm{wk}$ & 17 & 22 & & 8 & 25 & \\
\hline \multicolumn{7}{|l|}{ Birth weight $z$ score } \\
\hline$>-1$ & 78 & 80 & 0.52 & 75 & 82 & 0.02 \\
\hline$\leq-1$ & 20 & 14 & & 16 & 14 & \\
\hline$\leq-2$ & 2 & 5 & & 9 & 4 & \\
\hline Male & 50 & 53 & 0.40 & 56 & 52 & 0.19 \\
\hline Singleton & 76 & 74 & 0.45 & 70 & 75 & 0.10 \\
\hline \multicolumn{7}{|l|}{$\mathrm{T} 4<5.3 \mu / \mathrm{dL}$} \\
\hline Yes & 46 & 26 & 0.01 & 40 & 24 & $<0.001$ \\
\hline Missing & 4 & 4 & & 6 & 4 & \\
\hline Respiratory distress syndrome & 87 & 82 & 0.24 & 91 & 80 & $<0.001$ \\
\hline Surfactant treatment & 43 & 38 & 0.27 & 67 & 31 & $<0.001$ \\
\hline Ventilation $>7 \mathrm{~d}$ & 63 & 39 & 0.001 & 83 & 30 & $<0.001$ \\
\hline Highest $\mathrm{FIO}_{2}=100 \%$ & 44 & 39 & 0.29 & 65 & 34 & $<0.001$ \\
\hline Highest $\mathrm{PCO}_{2}>60 \mathrm{~mm} \mathrm{Hg}$ & 16 & 21 & 0.27 & 18 & 22 & 0.01 \\
\hline Lowest $\mathrm{PCO}_{2}<35 \mathrm{~mm} \mathrm{Hg}$ & 75 & 88 & 0.02 & 76 & 55 & $<0.001$ \\
\hline Lowest $\mathrm{PCO}_{2}<30 \mathrm{~mm} \mathrm{Hg}$ & 52 & 34 & 0.01 & 44 & 33 & 0.005 \\
\hline Lowest $\mathrm{PCO}_{2}<25 \mathrm{~mm} \mathrm{Hg}$ & 32 & 13 & 0.002 & 19 & 13 & 0.04 \\
\hline
\end{tabular}

$\mathrm{FIO}_{2}$, fraction of inspired oxygen.

mation. We also calculated univariable and gestational ageadjusted odds ratios (ORs) for WMD for each covariable that remained in the full model.

To adjust for potential confounders, including factors associated with the need for prolonged ventilatory assistance and its consequences, we created a confounder/propensity score for ventilation lasting more than $7 \mathrm{~d}$. Confounder/propensity scores may be used to adjust for what has led to a specific treatment (here, long ventilation) in models in which the treatment is an independent variable (33). The goal is to avoid bias by indication, i.e. attributing to a treatment what should be attributed to what led to the treatment. To calculate such a confounder/propensity score for each newborn, we created a logistic regression model that predicted ventilation for more than $1 \mathrm{wk}$. The following predictor variables were used in this model because we considered them characteristics that might be associated with an infant's need for prolonged assisted ventilation or its consequences: gestational age, absence of antenatal steroid treatment, hypothyroxinemia (defined as a first measured thyroxine level below $5.3 \mu \mathrm{g} / \mathrm{dL}$, the cutoff for the lowest quartile in the original cohort (34)), respiratory distress syndrome, intraventricular hemorrhage, surfactant treatment, hypocarbia, neonatal acidemia, a fraction of inspired oxygen of 1.0, severe apnea, persistent ductus arteriosus, and systemic hypotension. The predicted likelihood of ventilation derived from this model (a number between 0 and 1 ) for each 
Table 4. Column percentages of infants with/without WMD and with/without BPD whose placenta had the characteristic listed on the left

\begin{tabular}{|c|c|c|c|c|c|c|}
\hline & \multicolumn{3}{|c|}{ WMD } & \multicolumn{3}{|c|}{ BPD } \\
\hline Histologic chorioamnionitis & 39 & 40 & 0.71 & 37 & 41 & 0.67 \\
\hline $\begin{array}{l}\text { Fetal vasculitis (in subsample with } \\
\text { rupture of membranes }<1 \mathrm{~h} \text { )* }\end{array}$ & 25 & 14 & 0.05 & 10 & 16 & 0.35 \\
\hline $\begin{array}{l}\text { Fetal vasculitis (in subsample with } \\
\text { rupture of membranes } \geq 1 \mathrm{~h} \text { ) }\end{array}$ & 38 & 42 & 0.87 & 48 & 40 & 0.22 \\
\hline Increased syncytial knots & 13 & 16 & 0.49 & 22 & 14 & 0.03 \\
\hline Old infarcts & 3 & 10 & 0.27 & 13 & 9 & 0.12 \\
\hline
\end{tabular}

* Infants whose fetal vasculitis is unlikely to be a response to an infection ascending via the ruptured membranes but a response to longstanding infection present before membrane rupture.

child is her or his confounder/propensity score in subsequent regression models that had WMD as the outcome/dependent variable.

\section{RESULTS}

Co-occurrence. The observed number of infants with both WMD and BPD $(n=10)$ was not appreciably higher than would be expected if the two were unrelated $(n=9)$. Moreover, in strata of gestational age, observed and expected numbers were exactly the same. Thus, the occurrences of WMD and BPD seem to be independent of each other (Table 1).

Maternal characteristics. No maternal characteristic was prominently associated with an increased risk of both WMD and BPD. Indeed, in some cases, the associations, although not strong, were in opposite directions. For example, cesarean section was associated with reduced risk of WMD and increased risk of BPD. The situation was reversed for "any antibiotic." Maternal receipt during this admission of an antibiotic was associated with increased risk of echolucency and decreased risk of bronchopulmonary dysplasia (Table 2).

Infant characteristics. Infant characteristics associated with both WMD and BPD included low gestational age, neonatal hypothyroxinemia, ventilation for more than $1 \mathrm{wk}$, and hypocarbia. Respiratory distress syndrome and surfactant receipt were associated with BPD but not with WMD near the usual $p$ $<0.05$ level (Table 3).

Placenta characteristics. Although fetal vasculitis was not associated with WMD in the entire sample, among infants who were born within $1 \mathrm{~h}$ of membrane rupture, those whose placenta had fetal vasculitis were at increased risk of WMD but not BPD. Conversely, increased syncytial knots were associated with increased risk of BPD but not with WMD (Table 4).

Multivariable relationships. As expected, logistic regression modeling revealed no association between BPD and WMD. When we adjusted for potential confounders identified in the univariable analyses described above, we arrived at a multivariable model for WMD in which ventilation for more than $7 \mathrm{~d}$ was the only variable with an OR that exceeded 2.0 (Table 5). However, the OR for long ventilation dropped to 1.8 [95\% confidence interval (CI), 0.8-4.2] when we added the confounder/propensity score for long ventilation to the multivariable model, thereby adjusting for what might have led to the extended time on the ventilator (data not shown). In a model that included only long ventilation and the propensity/ confounder score as antecedent variables, the OR for long ventilation was 1.6 ( $95 \% \mathrm{CI}, 0.7-3.6)$, whereas the propensity score itself achieved an OR of 4.4 (95\% CI, 1.1-17).

\section{DISCUSSION}

Some of the first claims that respiratory care might influence the risk of structural brain abnormalities focused on brain abnormalities identified on postmortem examination (35) and intraventricular hemorrhage (36). The focus has since shifted to sonographic evidence of WMD and late clinical outcomes, mainly cerebral palsy $(\mathrm{CP})$.

Previous results have not been consistent regarding a cooccurrence of BPD and WMD/CP. Results from most univariable analyses have not demonstrated an appreciable difference in the prevalence of cranial ultrasound abnormalities (e.g. intracranial hemorrhage, periventricular leukomalacia) in infants with BPD compared with control subjects $(37,38)$. In one univariable study (39), subependymal hemorrhage was present in $6 \%$ of BPD cases and $3 \%$ of control subjects. In a study that used multivariable techniques, periventricular leukomalacia was present in $5 \%$ of infants with BPD defined as oxygen requirement at $36 \mathrm{wk}$ gestational age and in $6 \%$ of infants with BPD defined as need for supplementary oxygen at $28 \mathrm{~d}$, compared with $7 \%$ among control subjects (38).

In four studies, the incidence of CP was higher among infants with BPD than among control subjects $(15,40-42)$. In one other study, the incidence of $\mathrm{CP}$ was higher in control subjects (24\%) than among cases of BPD (14\%) (43). How-

Table 5. ORs (95\% CIs) in univariable and multivariable logistic regression models for $W M D$

\begin{tabular}{lccc}
\hline & Univariable & $\begin{array}{c}\text { Adjusted for } \\
\text { gestational } \\
\text { age }<26 \mathrm{wk}\end{array}$ & $\begin{array}{c}\text { Adjusted for } \\
\text { all variables } \\
\text { listed }\end{array}$ \\
\hline \multicolumn{1}{c}{ Predictor variable } & $1.2(0.6-2.5)$ & $1.1(0.5-2.3)$ & $0.7(0.3-1.5)$ \\
$\begin{array}{l}\text { Respiratory distress } \\
\quad \text { syndrome }\end{array}$ & $1.5(0.6-3.6)$ & $1.3(0.5-3.1)$ & - \\
$\quad$ Ventilation $>7 \mathrm{~d}$ & $2.7(1.5-5.0)$ & $2.3(1.2-4.5)$ & $2.2(1.04-4.8)$ \\
$\quad \begin{array}{l}\text { Gestational age }<26 \mathrm{wk} \\
\text { White blood cell count }\end{array}$ & $2.2(1.2-4.1)$ & - & $1.4(0.7-2.8)$ \\
$\quad 1.7(0.0-3.1)$ & $1.6(0.9-3.1)$ & $1.8(0.9-3.4)$ \\
$\quad \begin{array}{l}\mathrm{T} 4 \\
\mathrm{~L} 45.000\end{array}$ & $2.5(1.3-4.6)$ & $2.2(1.2-4.1)$ & $1.9(1.0-3.7)$ \\
Lowest $\mathrm{PCO}_{2}<30 \mathrm{~mm} \mathrm{Hg}$ & $2.1(1.2-3.9)$ & $1.9(1.04-3.6)$ & $1.6(0.9-3.1)$ \\
\hline
\end{tabular}


ever, none of these studies included multivariable data analyses that adjusted for potential confounders of the association between BPD and CP. Moreover, none had a sample size that appreciably exceeded 250 .

The apparent discrepancy between short-term and long-term outcome studies has multiple explanations. First, a general caveat: we do not know the number of long-term "negative results" studies that remain unpublished.

Second, in regional or multicenter studies, only $50 \%$ of preterm infants with $\mathrm{CP}$ have abnormal cranial ultrasound images (44-46). Thus, the sensitivity of early ultrasound might be too low to detect all WMD relevant to later developmental disability. Ultrasound examination of the brain can identify gross necrotic lesions of cerebral white matter (2023). It is much less able to identify the early diffuse WMD discernible on diffusion-weighted magnetic resonance imaging (MRI) (47). Thus, sonographically defined WMD represents only "the tip of the iceberg" of all WMD (48). In light of this disparity between ultrasound and MRI images, it is possible that infants who develop diffuse WMD early without an ultrasound signature are at increased risk of BPD. Perhaps these are some of the BPD children who later display neurodevelopmental difficulties $(15,40)$.

Third, some ultrasound-defined neonatal brain abnormalities might not suffice to produce long-term disability, because the amount of damage is small, because the immature brain is capable of repair, or because endogenous protectors (49) limit the ability of neonatal brain damage to induce secondary neuroinflammatory cascades that contribute to long-term disturbance in function.

In this article, we do not look at CP but at what might be its closest antecedent, namely, cerebral WMD defined by an echolucency identified on neonatal cranial ultrasound. Although we found no association between respiratory distress syndrome or BPD and WMD, we acknowledge that there might still be an association between BPD and CP.

Because we did not find an association between lung disease and brain damage, we searched for relationships between ventilation-associated variables and WMD. The only associations that we could identify were one that we had previously reported between hypocarbia and WMD (22) and one, not previously reported, between prolonged ventilatory support and echolucency of the white matter. As with hypocarbia (22), the risk estimate for the association between long ventilation and WMD (OR, 2.2; 95\% CI, 1.04-4.8) decreased more than $10 \%$ once we adjusted with a confounder/propensity score (OR, 1.6; 95\% CI, 0.7-3.6). This leads us to speculate that, in this model, the variables associated with prolonged ventilatory support might convey some information about an infant's immaturity-associated severity of illness that is not captured by the joint effect of long ventilation, gestational age, and the other confounders in the model.

Still, in our final model (Table 5), prolonged ventilation was associated with an increased WMD risk, whereas BPD was associated with a slightly reduced WMD risk. Some of this risk reduction associated with BPD might reflect the tendency of both the BPD and the prolonged ventilation variables to share information. Thus, including one reduces the contribution of the other. Some of this risk reduction associated with BPD might be due to the absence of WMD among infants with BPD who had been ventilated for less than $1 \mathrm{wk}(n=28)$, whereas $10(7 \%)$ of 140 infants with BPD and ventilation for more than $1 \mathrm{wk}$ had WMD. Apparently, not all BPD is equal when it comes to WMD risk. One simplistic explanation is that "mild" BPD might carry a lower WMD risk than "severe" BPD. We were not able to distinguish between mild and severe BPD in our analyses above and beyond our appreciation of BPDassociated characteristics such as long ventilation. Clearly, the need for prolonged ventilation tells us more about WMD risk than does need for supplemental oxygen at 36 wk. However, adjustment for a propensity/confounder score based on variables associated with the need for and the consequences of prolonged ventilation led to an appreciable reduction of the OR for prolonged ventilation.

In our univariable analyses, infants whose placenta had membrane inflammation were not at increased risk of WMD or BPD. Others, however, have reported that chorioamnionitis is an antecedent of echolucency (50). Virtually all placentas and umbilical cords that have fetal vasculitis also have inflammation of the membranes, but only approximately half of placentas with membrane inflammation have fetal vasculitis $(21,51)$. This and other findings have led to our view that fetal vasculitis is an indication of the severity and progression of the inflammatory process that tends to involve the membranes before it involves the chorionic plate and umbilical cord. Fetal vasculitis, then, is documentation that the fetus has responded to the inflammatory insult. This suggests that chorioamnionitis is an antecedent of echolucency but only when the chorioamnionitis is sufficiently severe to result in a fetal response, evident as fetal vasculitis. Some of the resulting inflammation needs to be systemic to influence the risk of brain and lung damage.

Expanding on the finding that chorioamnionitis is associated with an increased risk of BPD (52), we recently reported that chorioamnionitis alone reduces the risk of BPD (OR, 0.6; 95\% CI, 0.4-1.03) (26) but that the synergistic effects of chorioamnionitis with long ventilation (OR, 3.2; 95\% CI, 0.9-11) and postnatal sepsis (OR, 2.9; 95\% CI, 1.1-7.7) seem to work in the opposite direction. Although we (26) and others (53) did not find that fetal vasculitis is an antecedent of BPD, some investigators have reported such an association. In one very small study, all five infants with necrotizing funisitis developed BPD, compared with only one third of infants without necrotizing funisitis (54). In another study, BPD (grouped with Wilson-Mikity Syndrome) was equally common in infants with (28\%) and without (33\%) subacute necrotizing funisitis (55).

In this study, increased syncytial knots in the placenta are associated with BPD but not with WMD. Syncytial knots are aggregations of nuclei in the syncytiotrophoblast layer of the placental membrane that covers the fetal branch villi (56). Increased syncytial knots are associated with low uteroplacental blood flow (57), maternal smoking (58), and fetal growth restriction and pregnancy-induced hypertension (30). One possible interpretation is that increased syncytial knots might be a marker of the absence of chorioamnionitis (see above). Another could be that fetal growth restriction is indeed associated with an intrinsically increased risk of BPD (59). 
Taken together with our findings about the chorioamnionitis-BPD relationship, the possibility exists that the risks of both WMD and BPD originate after an inflammatory intrauterine insult. What happens after, however, probably depends on other risk factors that modulate these risks.

Our not finding sufficient support for the hypothesis that BPD and neonatal WMD are associated has at least two components. First, we found only an ever-so-slight difference in BPD prevalence among infants with WMD (22\%) compared with infants without WMD (19\%), which is somewhat unlikely to bear clinical relevance. Second, this minuscule difference between $22 \%$ and $19 \%$ did not achieve nominal statistical significance. According to a post hoc calculation, this difference would be significant at an $\alpha$ level of 0.05 with $90 \%$ power if one compared 2,016 cases of WMD with 37,599 controls. Currently, even meta-analytic approaches are unlikely to achieve such large numbers.

One might still ask, "Why aren't BPD and WMD related?" We would like to ask, "Why should they be related?"

One answer is that because both are associated with prematurity, one would expect them to co-occur in preterm infants. We did not find support for this hypothesis in our data set of infants who were born at less than $30 \mathrm{wk}$ gestation.

Another possible answer is that one might assume that lung disorders cause hypoxia, which in turn causes WWD. Although we do not subscribe to this line of thinking, we still consider it too simplistic to take the extreme view and assume that most of what causes WMD occurs antenatally and most of what causes BPD occurs postnatally. Nevertheless, if we did, then we would infer that BPD cannot be a causal factor in WMD (because outside the world of theoretical physics an effect rarely precedes its cause). However, we do believe that the data presented in this article are in agreement with previous challenges (9) to the view that lung disease-associated phenomena contribute to the occurrence of brain WMD.

\section{CONCLUSION}

In summary, we did not find that the antecedents of BPD are antecedents of sonographically defined WMD. Because infants with BPD seem to be at increased risk of some neurodevelopmental disorders that are known consequences of WMD, it is possible that the link between WMD and BPD is limited to the diffuse forms of WMD not detectable by ultrasound but evident on diffusion-weighted MRI (47).

Acknowledgments The Developmental Epidemiology Network Investigators are as follows. Executive Committee: Alan Leviton, Nigel Paneth, M. Lynne Reuss, and Mervyn Susser; Neonatology Committee: Thomas Hegyi, Mark Hiatt, Ulana Sanocka, Farrokh Shahrivar, and Linda J. Van Marter; Ultrasound Committee: Michael Abiri, Donald DiSalvo, Peter Doubilet, Ram Kairam, Elias Kazam, Madhuri Kirpekar, David Rosenfeld, Steven Schonfeld, and Jane Share; Placenta Pathology Committee: Petra Banogan, Margaret Collins, David R. Genest, Debra Heller, and Susan Shen-Schwarz; Data Analysis Committee: Elizabeth N. Allred, Olaf Dammann, Karl C.K. Kuban, Alan Leviton, and Marcello Pagano.
We thank the parents, the children, and our colleagues who contributed to the success of this study.

\section{REFERENCES}

1. Northway WH Jr, Rosan RC, Porter DY 1967 Pulmonary disease following respirator therapy of hyaline-membrane disease. Bronchopulmonary dysplasia. N Engl J Med 276:357-368

2. Jobe AJ 1999 The new BPD: an arrest of lung development. Pediatr Res 46:641-643

3. Jobe AH 2003 Antenatal factors and the development of bronchopulmonary dysplasia. Semin Neonatol 8:9-17

4. Speer CP 2003 Inflammation and bronchopulmonary dysplasia. Semin Neonatol 8:29-38

5. Bancalari E, Claure N, Sosenko IRS 2003 Bronchopulmonary dysplasia: changes in pathogenesis, epidemiology and definition. Semin Neonatol 8:63-71

6. Shennan AT, Dunn MS, Ohlsson A, Lennox K, Hoskins EM 1988 Abnormal pulmonary outcomes in premature infants: prediction from oxygen requirement in the neonatal period. Pediatrics 82:527-532

7. Avery ME, Tooley WH, Keller JB, Hurd SS, Bryan MH, Cotton RB, Epstein MF, Fitzhardinge PM, Hansen CB, Hansen TN, et al. 1987 Is chronic lung disease in low birth weight infants preventable? A survey of eight centers. Pediatrics 79:26-30

8. Leviton A, Paneth N 1990 White matter damage in preterm newborns - an epidemiologic perspective. Early Hum Dev 24:1-22

9. Kuban KC 1998 White-matter disease of prematurity, periventricular leukomalacia, and ischemic lesions. Dev Med Child Neurol 40:571-573

10. Volpe JJ 2001 Neurobiology of periventricular leukomalacia in the premature infant. Pediatr Res 50:553-562

11. Dammann O, Leviton A 2000 Role of the fetus in perinatal infection and neonatal brain damage. Curr Opin Pediatr 12:99-104

12. Lyon A 2000 Chronic lung disease of prematurity. The role of intra-uterine infection. Eur J Pediatr 159:798-802

13. Brand MM, Bignami A 1969 The effects of chronic hypoxia on the neonatal and infantile brain. A neuropathological study of five premature infants with the respiratory distress syndrome treated by prolonged artificial ventilation. Brain 92:233-254

14. Perlman JM, Volpe JJ 1989 Movement disorder of premature infants with severe bronchopulmonary dysplasia: a new syndrome. Pediatrics 84:215-218

15. Majnemer A, Riley P, Shevell M, Birnbaum R, Greenstone H, Coates AL 2000 Severe bronchopulmonary dysplasia increases risk for later neurological and motor sequelae in preterm survivors. Dev Med Child Neurol 42:53-60

16. Wilson-Costello D 2001 Risk factors for neurologic impairment among very lowbirth-weight infants. Semin Pediatr Neurol 8:120-126

17. Davis JM, Rosenfeld WN 1999 Chronic lung disease. In: Avery GB, Fletcher MA, MacDonald MG (eds) Neonatology: Pathophysiology and Management of the Newborn. Lippincott Williams \& Wilkins, Philadelphia. pp 509-532

18. Arnold CC, Kramer MS, Hobbs CA, McLean FH, Usher RH 1991 Very low birth weight: a problematic cohort for epidemiologic studies of very small or immature neonates. Am J Epidemiol 134:604-613

19. Teele R, Share J 1991 Ultrasonography of Infants and Children. Saunders, Philadelphia

20. Kuban K, Leviton A, Allred E, Pagano M, Dammann O, the Developmental Epidemiology Network Investigators 1998 Occurrence and topography of white matter disease of prematurity. Ann Neurol 44:536

21. Leviton A, Paneth N, Reuss ML, Susser M, Allred EN, Dammann O, Kuban K, Van Marter LJ, Pagano M, Hegyi T, Hiatt M, Sanocka U, Shahrivar F, Abiri M, DiSalvo D, Doubilet P, Kairam R, Kazam E, Kirpekar M, Rosenfeld D, Schonfeld S, Share J, Collins M, Genest D, Heller D, Shen-Schwarz S 1999 Maternal infection, fetal inflammatory response, and brain damage in very low birthweight infants. Pediatr Res 46:566-575

22. Dammann O, Allred EN, Kuban KCK, Van Marter LJ, Pagano M, Leviton A, for the Developmental Epidemiology Network 2001 Hypocarbia during the first 24 postnatal hours and periventricular echolucencies in newborns $<28$ weeks gestation. Pediatr Res 49:388-393

23. Dammann O, Allred EN, Kuban KC, Van Marter LJ, Pagano M, Sanocka U, Leviton A 2002 Systemic hypotension and white-matter damage in preterm infants. Dev Med Child Neurol 44:82-90

24. Van Marter LJ, Allred EN, Pagano M, Sanocka U, Parad R, Moore M, Susser M, Paneth N, Leviton A 2000 Do clinical markers of barotrauma and oxygen toxicity explain interhospital variation in rates of chronic lung disease? The Neonatology Committee for the Developmental Network. Pediatrics 105:1194-1201

25. Van Marter LJ, Allred EN, Leviton A, Pagano M, Parad R, Moore M 2001 Antenatal glucocorticoid treatment does not reduce chronic lung disease among surviving preterm infants. J Pediatr 138:198-204

26. Van Marter LJ, Dammann O, Allred EN, Leviton A, Pagano M, Moore M, Martin C 2002 Chorioamnionitis, mechanical ventilation, and postnatal sepsis as modulators of chronic lung disease in preterm infants. J Pediatr 140:171-176

27. Hansen A, Leviton A, for the Developmental Epidemiology Network Investigators 1998 The correlation between placental pathology and intraventricular hemorrhage in the preterm infant. Pediatr Res 43:15-19

28. Grether JK, Eaton A, Redline R, Bendon R, Benirschke K, Nelson K 1999 Reliability of placental histology using archived specimens. Paediatr Perinat Epidemiol 13:489495

29. Hansen AR, Collins MH, Genest D, Heller D, Shen-Schwarz S, Banagon P, Allred EN, Leviton A 2000 Very low birthweight placenta: clustering of morphologic characteristics. Pediatr Dev Pathol 3:431-438 
30. Hansen AR, Collins MH, Genest D, Heller D, Schwarz S, Banagon P, Allred EN, Leviton A 2000 Very low birthweight infant's placenta and its relation to pregnancy and fetal characteristics. Pediatr Dev Pathol 3:419-430

31. Hill AB 1961 Problems of sampling: chi-square. In: Principles of Medical Statistics Oxford University Press, New York, pp 152-161

32. Dales LG, Ury HK 1978 An improper use of statistical significance testing in studying covariables. Int J Epidemiol 7:373-375

33. Rubin DB 1997 Estimating causal effects from large data sets using propensity scores. Ann Intern Med 127:757-763

34. Leviton A, Paneth N, Reuss ML, Susser M, Allred EN, Dammann O, Kuban K, Van Marter LJ, Pagano M, for The Developmental Epidemiology Network Investigator 1999 Hypothyroxinemia of prematurity and the risk of cerebral white matter damage. J Pediatr 134:706-711

35. Brand MM, Durbridge TC, Rosan RC, Northway WH Jr 1972 Neuropathological lesions in respiratory distress syndrome: acute and chronic changes during hypoxia and oxygen therapy. J Reprod Med 8:267-279

36. Perlman JM, McMenamin JB, Volpe JJ 1983 Fluctuating cerebral blood-flow velocity in respiratory distress syndrome. N Engl J Med 309:204-209

37. Rojas MA, Gonzalez A, Bancalari E, Claure N, Poole C, Silva-Neto G 1995 Changing trends in the epidemiology and pathogenesis of neonatal chronic lung disease. J Pediatr 126:605-610

38. Gregoire MC, Lefebvre F, Glorieux J 1998 Health and developmental outcomes at 18 months in very preterm infants with bronchopulmonary dysplasia. Pediatrics 101:856-860

39. O'Shea TM, Goldstein DJ, deRegnier RA, Sheaffer CI, Roberts DD, Dillard RG 1996 Outcome at 4 to 5 years of age in children recovered from neonatal chronic lung disease. Dev Med Child Neurol 38:830-839

40. Skidmore MD, Rivers A, Hack M 1990 Increased risk of cerebral palsy among very low-birthweight infants with chronic lung disease. Dev Med Child Neurol 32:325-332

41. Vohr BR, Coll CG, Lobato D, Yunis KA, O’Dea C, Oh W 1991 Neurodevelopmental and medical status of low-birthweight survivors of bronchopulmonary dysplasia at 10 to 12 years of age. Dev Med Child Neurol 33:690-697

42. Gray PH, Burns YR, Mohay HA, O'Callaghan MJ, Tudehope DI 1995 Neurodevelopmental outcome of preterm infants with bronchopulmonary dysplasia. Arch Dis Child Fetal Neonatal Ed 73:F128-F134

43. Robertson CM, Etches PC, Goldson E, Kyle JM 1992 Eight-year school performance, neurodevelopmental, and growth outcome of neonates with bronchopulmonary dysplasia: a comparative study. Pediatrics 89:365-372

44. Pinto-Martin JA, Riolo S, Cnaan A, Holzman C, Susser MW, Paneth N 1995 Cranial ultrasound prediction of disabling and nondisabling cerebral palsy at age two in a low birth weight population. Pediatrics 95:249-254
45. O'Shea TM, Klinepeter KL, Dillard RG 1998 Prenatal events and the risk of cerebral palsy in very low birth weight infants. Am J Epidemiol 147:362-369

46. Wheater M, Rennie JM 2000 Perinatal infection is an important risk factor for cerebral palsy in very-low-birthweight infants. Dev Med Child Neurol 42:364-367

47. Inder T, Hüppi PS, Zientara GP, Maier SE, Jolesz FA, di Salvo D, Robertson R, Barnes PD, Volpe JJ 1999 Early detection of periventricular leukomalacia by diffusion-weighted magnetic resonance imaging techniques. J Pediatr 134:631-634

48. Holling EE, Leviton A 1999 Characteristics of cranial ultrasound white matter echolucencies that predict disability: a review. Dev Med Child Neurol 41:136-139

49. Dammann O, Leviton A 1999 Brain damage in preterm newborns: might enhancement of developmentally-regulated endogenous protection open a door for prevention? Pediatrics 104:541-550

50. Wu YW 2002 Systematic review of chorioamnionitis and cerebral palsy. Ment Retard Dev Disabil Res Rev 8:25-29

51. Yanowitz TD, Jordan JA, Gilmour CH, Towbin R, Bowen A, Roberts JM, Brozanski BS 2002 Hemodynamic disturbances in premature infants born after chorioamnionitis: association with cord blood cytokine concentrations. Pediatr Res 51:310-316

52. Watterberg KL, Demers LM, Scott SM, Murphy S 1996 Chorioamnionitis and early lung inflammation in infants in whom bronchopulmonary dysplasia develops. Pediatrics 97:210-215

53. Redline RW, Wilson-Costello D, Hack M 2002 Placental and other perinatal risk factors for chronic lung disease in very low birth weight infants. Pediatr Res 52:713-719

54. Matsuda T, Nakajima T, Hattori S, Hanatani K, Fukazawa Y, Kobayashi K, Fujimoto S 1997 Necrotizing funisitis: clinical significance and association with chronic lung disease in premature infants. Am J Obstet Gynecol 177:1402-1407

55. Ohyama M, Itani Y, Yamanaka M, Goto A, Kato K, Ijiri R, Tanaka Y 2002 Re-evaluation of chorioamnionitis and funisitis with a special reference to subacute chorioamnionitis. Hum Pathol 33:183-190

56. Moore KL, Persaud TVN 1993 The Developing Human: Clinically Oriented Embryology. W.B. Saunders, Philadelphia

57. Naeye RL 1989 Pregnancy hypertension: placental evidences of low uteroplacental blood flow, and spontaneous premature delivery. Hum Pathol 20:441-444

58. Demir R, Demir AY, Yinanc M 1994 Structural changes in placental barrier of smoking mother. A quantitative and ultrastructural study. Pathol Res Pract 190:656667

59. Gortner L, Wauer RR, Stock GJ, Reiter HL, Reiss I, Jorch G, Hentschel R, Hieronimi G 1999 Neonatal outcome in small for gestational age infants: do they really better? J Perinat Med 27:484-489 